\title{
Using Monte Carlo Simulation for Prediction of Tool Life
}

\author{
Sayyad Zahid Qamar'1, Anwar Khalil Sheikh², \\ Tasneem Pervez ${ }^{1}$ and Abul Fazal M. Arif ${ }^{2}$ \\ ${ }^{1}$ Mechanical and Industrial Engineering Department, \\ Sultan Qaboos University, Muscat, \\ ${ }^{2}$ Mechanical Engineering Department, \\ King Fahd University of Petroleum and Minerals, Dhahran, \\ 1 Oman \\ ${ }^{2}$ Saudi Arabia
}

\section{Introduction}

Hot metal forming (rolling, forging, extrusion, wire drawing) constitutes a very large proportion of manufacturing activity. Of all the equipment and tooling involved in a hot forming process, the most critical component is usually considered to be the die due to its superior precision and reliability requirement and the associated high cost. Dies and ancillary tooling are exposed to high pressures, elevated temperatures, and both mechanical and thermal fatigue. Cost and engineering difficulty are obviously high because of factors such as special material and processing, very fine tolerances, and high demands on repeated thermo-mechanical performance. How often a die has to be scrapped and replaced with a new one directly contributes to the commercial viability of producing a certain profile, not only because of the large cost of die replacement, but also because of losses due to interrupted production and reduced product quality in the case of a defective die.

Due to this critical importance and high cost of metal forming tools, one of the major goals is a longer tool life. Continued research in tool and process design is therefore targeted at minimization of tool failure. However, tool failure is a complex phenomenon, governed by an interaction of various mechanisms, and not easy to control or restrain. A more manageable approach is to make die failure predictable. Estimation and prediction of tool life thus become crucially important.

Extrusion is one of the most popular metal forming processes. Because of its wide-ranging and abundant application in the automobile, aircraft, and construction industries, aluminum has been called the metal of the millennium. As extrusion is the primary manufacturing process for aluminum alloys, the popularity and importance of extrusion has increased even more. The three leading failure mechanisms for extrusion dies are fracture, wear, and plastic deformation (Bauser et al., 2006). Fatigue fracture and gradual wear are the more dominant of these failure modes. 


\subsection{Fatigue fracture}

As established in an earlier work by the authors (Arif et al., 2003), fracture is the principal failure mode for extrusion dies and tooling (solid, hollow, and semi-hollow die profiles all taken together). An extrusion die experiences both mechanical and thermal stresses during its service life. As temperature changes are rather gradual, thermal stresses due to temperature differences are generally not very critical. Mechanical stresses are cyclic in nature, going from zero to maximum and back during extrusion of each billet. The maximum stress in aluminum extrusion can be around 27,000 psi or $186 \mathrm{MPa}$ (Laue and Stenger, 1981). At the beginning of each extrusion cycle (after loading a fresh billet into the container), the pressure applied by the ram of the extrusion press swiftly reaches a maximum value, the operation being known as upsetting. As extrusion proceeds, the pressure gradually decreases to an approximately constant value; the steady-state portion of the process. Towards the end of each cycle, pressure may increase again, during butt removal or discard rejection (removal of the end portion of the billet). These cyclic stresses, in the presence of some pre-existing flaws (such as micro cracks produced during heat treatment), can lead to crack growth and ultimate fatigue failure. The failure mechanism is influenced by

a. material properties, geometric tolerances, and surface finish of the billet;

b. material properties, heat treatment and surface hardening, and geometrical details of the die and tooling;

c. stress distribution and variation with time and temperature during the extrusion process; and

d. stiffness and kinematics of the press and affiliated tooling.

Fatigue failures are mostly located at positions of high stress concentration such as sharp corners, section changes, stamp marks, etc.

Fig. 1 shows schematic and actual occurrence of the significant failure mechanisms for an extrusion die. The incidence of fatigue fracture is especially high for high extrusion ratios and small fillet radii, resulting in high stress concentration. Crack initiation may be further promoted by machining marks. Failure by forced rupture (due to overload) rarely occurs in practical applications, and can often be traced to human errors. Some aspects of fatigue and fracture failure in extrusion dies and tooling have been investigated by different researchers (Hambli and Badie-Levet, 2000; Gouveia et al., 2000; Sudhakar, 2002; Yoh et al., 2002; Cosenza et al., 2004; Tseronis et al., 2008; and Nanninga et al., 2009).

\subsection{Surface wear}

The second most significant failure mode in extrusion dies is gradual wear of the die bearing surface (Arif et al., 2003). A combination of factors such as intricate profile geometries, high pressures and temperatures, very hard die material, and extremely hard and abrasive surface layer of $\mathrm{Al}_{2} \mathrm{O}_{3}$ formed on the billet surface during preheating lead to wear at the die land. Die wear is a tribological effect and can be defined as the progressive loss or removal of material from the operating surface of tooling components (die bearing surface in our case). By changing the topography of the die land, wear can cause severe surface damage leading to product defects and finally die failure.

Both adhesive and abrasive wear mechanisms work together with sudden temperature fluctuations and prolonged exposures to elevated temperatures. Abrasive wear is more gradual, but is quite accelerated at high temperatures. Resulting die wash (wear) is at times aggravated by adhesive wear. It was reported by Thedja et al. (1992) that die wear begins on 

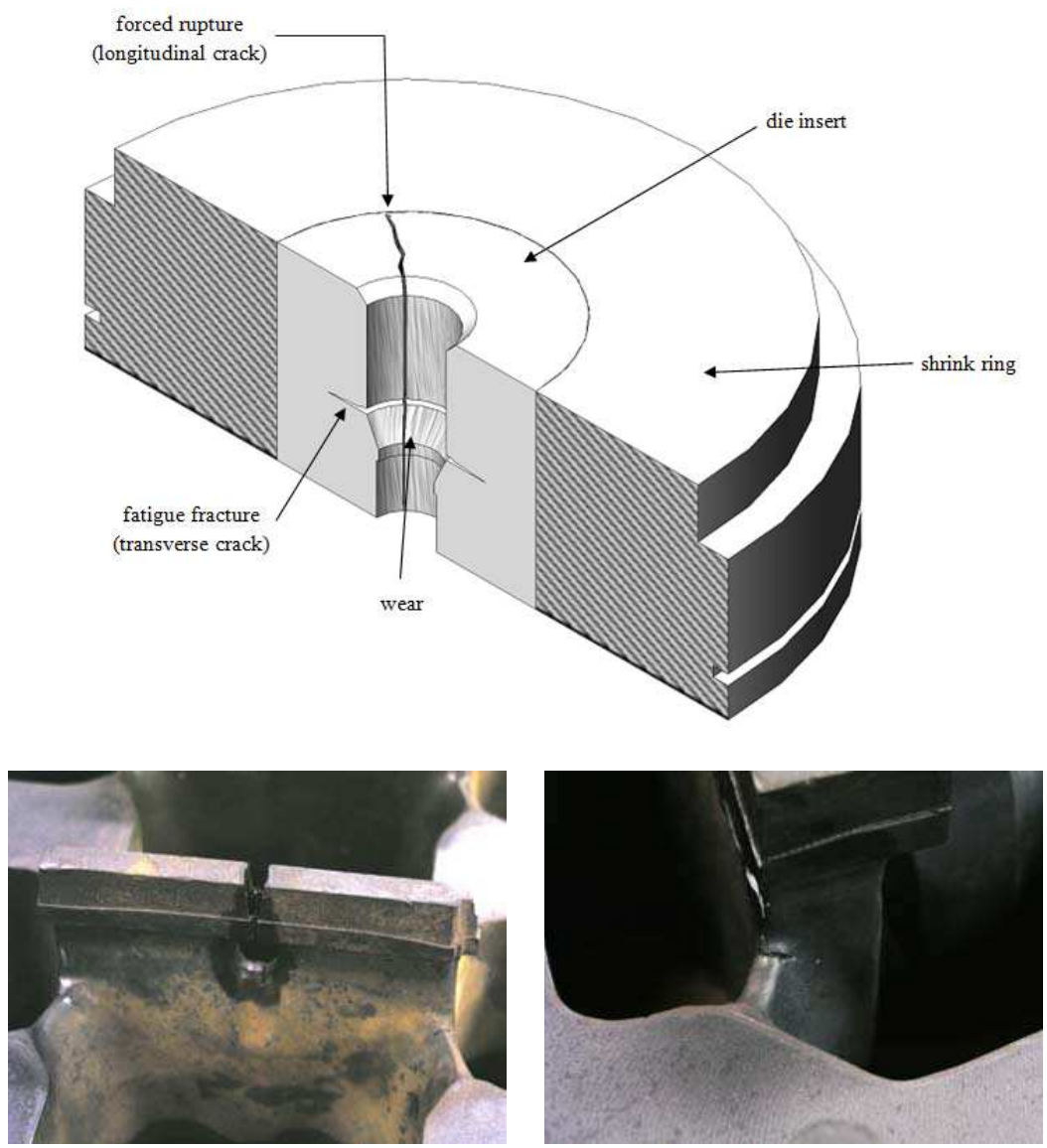

Fig. 1. Schematic and actual illustrations of fracture failure of dies in extrusion

the output side of the die bearing and progresses in a direction opposite to that of extrusion. According to other studies, the deepest wear traces can also be found at the leading edge (Saha, 1998) or in the middle (Björk et al., 2001). The disagreement in these findings is most likely caused by differences in extrusion conditions, bearing parameters, profile geometries, etc. Saha (1998) observed significant bearing washout (die wear) on a hollow die studied, and found that the wear increased at higher extrusion speeds. More wear spots were found on the mandrel bearing surface than on the cap bearing. Wear patterns observed by Thedja et al. (1992) in a hollow die are shown in Fig. 2. More detailed description of some aspects of die wear in extrusion and other metal forming dies can be found in Lee and Im (1999), Björk et al. (2001), Müller (2002), Terčelj et al. (2007), and So et al. (2008).

\subsection{Current work}

As mentioned earlier, the two most dominant failure mechanisms for extrusion dies are fracture and wear. Work presented here focuses on the development of life prediction models for extrusion dies based on fracture, wear, and combined fracture-wear failure 
mechanisms. In the first part of this chapter, a fracture mechanics based fatigue life prediction model is presented. A similar treatment is then presented for wear-related failures. Fracture and wear usually coexist as failure modes, and final die breakdown occurs due to the mechanism that becomes dominant. Therefore, a competing fracture-wear model has been later developed to represent the complete die failure situation.
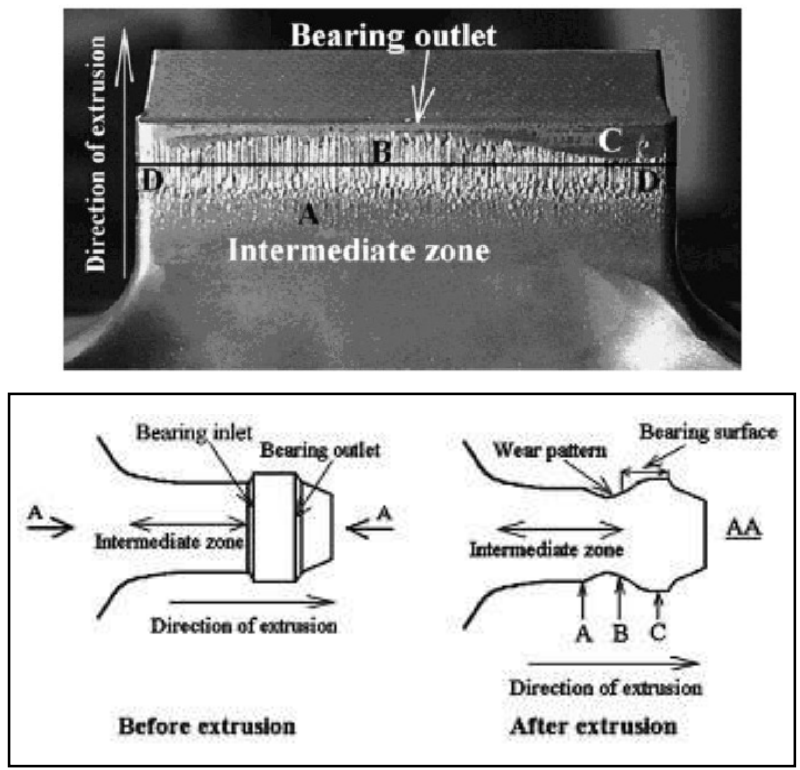

Fig. 2. Wear pattern in the mandrel of a hollow die (above); sketch showing mandrel before and after extrusion (below); longitudinal sectional view of the mandrel shows excessive wear (Thedja et al., 1992)

A probabilistic rather than a deterministic approach has been adopted (far closer to real behavior), with an attempt to correlate the stochastic nature of various fatigue and wear related die parameters to die life. Geometric features of the billet and tooling, their material properties, and relevant process parameters (extrusion pressure, ram speed, etc) are treated as random quantities. Nature of distributions and related parameters (mean, standard deviation, etc) for the different variables are determined from experimental and manufacturing data. The well-established Monte Carlo method is used to simulate instances of fracture, wear, and combined fracture-wear failures of the die for a given set of manufacturing conditions and mechanical properties. Case studies of actual hot aluminum extrusion from the industry are used for model development and validation. Two die profiles (a tube die and a box die) have been included, which are simple in geometry, but represent shape complexity to some degree, as hollow dies have a more complex extrusion setup than solid dies. The work can be extended to cover more complex profiles, thus providing life prediction for a die of a given profile before it is put to use. This life prediction can be very useful for developing optimum die replacement strategies in the industry, reducing warehousing costs significantly, and guarding against unnecessary downtime due to unavailability of a certain die profile. It can also contribute to improvement of die design by finding out expected failure times due to fracture and wear. 


\section{Case study}

Actual die failure data have been collected from a typical medium-to-large size commercial aluminum extrusion setup for two simple hollow dies. The tube die predominantly failed by fracture, and only a few times by wear; outer diameter $D_{0}=25.4 \pm(0.2,0.1) \mathrm{mm}$ and thickness is $t=1.6 \pm(0.15,0.1) \mathrm{mm}$. This die has been used to simulate fracture, wear, and combined fracture-wear failure mechanisms. The box die actually failed almost entirely due to die land wear; it is therefore used only for parameter estimation of wear failures; length of $40 \mathrm{~mm}$, width of $20 \mathrm{~mm}$, and thickness of $1.3 \pm(0.00,0.15) \mathrm{mm}$. Die material for both the dies was heat treated and surface hardened H13 steel, billet material being the soft grade aluminum alloy Al-6063 most commonly used in the construction sector. Average extrusion temperature was around $460^{\circ} \mathrm{C}$, and ram speed was $5 \mathrm{~mm} / \mathrm{s}$. The average die life (mean time to failure MTTF) for the tube die was 722 extrusion cycles, based on actual fracture failure data summarized in Table 1. Extrusion of each billet is considered to be one cycle, as the extrusion pressure goes from a minimum of zero to a maximum value, and then back to zero for each billet.

\begin{tabular}{|c|c|c|c|c|c|c|c|}
\hline Failure \# & 1 & 2 & 3 & 4 & 5 & 6 & 7 \\
\hline Cycles to Failure & 920 & 671 & 712 & 902 & 574 & 652 & 623 \\
\hline
\end{tabular}

Table 1 Various instances of number of billets/cycles to failure (due to fracture) for the tubedie studied

\section{Fatigue failure}

\subsection{Crack initiation}

In extrusion dies and tooling, cracks generally initiate at positions of high stress concentration such as section changes, sharp corners, stamp marks, etc. Crack initiation may be further promoted by machining marks. Due to manufacturing operations such as spark erosion (electric discharge machining EDM), there may be preexisting cracks, such as those shown in Fig. 3 (Pöhlandt and Kuehl, 1989). Depths of such cracks are typically about $0.01 \mathrm{~mm}$.

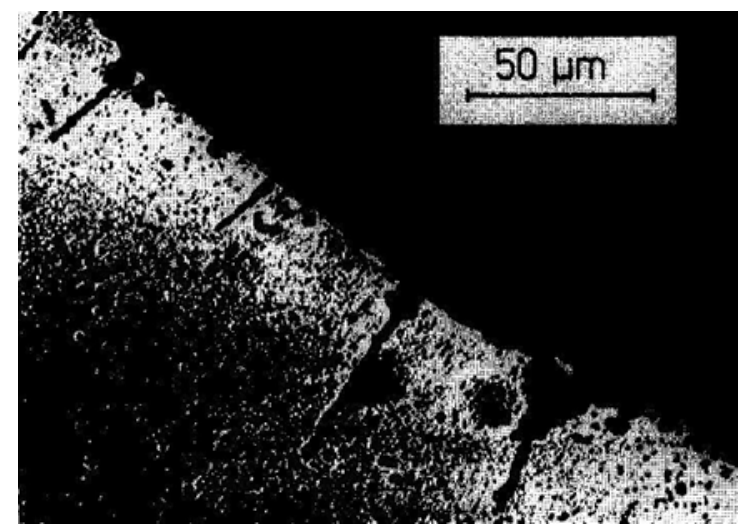

Fig. 3. Formation of fatigue cracks at the surface defects of spark eroded Cr-Mo-V steel (Pöhlandt, 1989) 
To improve wear resistance, die bearing surfaces are surface hardened, usually by nitriding. This nitriding process often results in the formation of small cracks of the order of $0.05 \mathrm{~mm}$ for H13 tool steels (Laue and Stenger, 1981). To achieve the desired combination of hardness and toughness characteristics, dies are subjected to specific heat treatment routines (hardening/austenitizing, tempering, quenching, etc). Existing small flaws usually get enlarged during these operations. With such initial pre-operation cracks (crack depths of 0.05 to $0.1 \mathrm{~mm}$ ), crack propagation takes over due to fatigue cycles during the actual extrusion process.

\subsection{Crack propagation}

Die fracture can be caused by one of two mechanisms. In the presence of an existing defect, a crack may take only a few cycles to reach the critical size, resulting in forced rupture (Fig. 1). This is known as hypercritical, instable crack growth. The other mechanism is subcritical, stable crack growth: from an existing defect, crack growth is caused by fatigue or creep (or a combination of the two), resulting in ultimate fracture. Both of these mechanisms are affected by different factors concerning the billet and die material, the process and the equipment. In hot extrusion, fatigue is the major contributor, effects of creep being negligible (Pöhlandt and Kuehl, 1989).

For components having subcritical cracks, fracture is almost of no concern as long as crack size is below the critical value under the given conditions. Under cyclic loading, crack propagation takes place until the stress intensity factor equals the fracture toughness of the die material. Large cyclic stresses, combined with regions of high stress concentration in cavities, lead to crack growth and ultimate failure. In general, cracks can grow only under tensile stresses, compressive stresses promoting crack closure and reduction of crack growth.

Three stages of crack growth are identified in fracture mechanics (Anderson, 2005). The first stage is the crack initiation or Stage-I crack growth. The second part is the Stage-II crack growth where a crack grows gradually and subcritically. Finally, when the fatigue crack grows to a length approaching the critical length for instability at the maximum applied stress level, the crack grows in an unstable fashion; the Stage-III crack growth region. Experimental studies show that fatigue crack growth data plot as a straight line on a log-log sale over Stage-II for a wide variety of metallic materials. Crack growth rate $\mathrm{d} a / \mathrm{d} N$, as a function of the applied stress intensity range $\Delta \mathrm{K}$, can be approximated by the famous Paris law proposed by Paris and Erdogan:

$$
d a / d N=C(\Delta K)^{m} .
$$

Value of $C$ depends on the system of units used for $\mathrm{d} a / \mathrm{d} N$ (mm/cycle or in/cycle) and $\Delta K$ (ksi $\sqrt{ }$ in or MPa $\sqrt{\mathrm{m}}$ ). For instance, for austenitic stainless steel, Barsom and Rolfe (1970) report $m=3.25$ and $C=5.60\left(10^{-2}\right)$ in mks and 3.0(10-10) in ips units. Values of the Paris constants $C$ and $m$ for a number of metals have been reported by Sanford (2003) and others. Influence of non-zero average stress has been neglected in this study.

\subsection{Fatigue life or cycles to failure}

It is well-known that (neglecting the finite size factor $f(a / W)$ for simplicity),

$$
\Delta K=\alpha \Delta \sigma \sqrt{\pi a},
$$


where $\Delta \sigma=\sigma_{\max }-\sigma_{\min }$. Since each extrusion cycle starts from a minimum load of zero, $\sigma_{\min }=0$. Thus, $\Delta \sigma=\sigma_{\max }$. Substituting equation (2) into (1), and rearranging, we get

$$
d N=\frac{d a}{C\left(\alpha \sigma_{\max } \sqrt{\pi a}\right)^{m}} .
$$

The fatigue life (or number of cycles to failure) can now be obtained by integrating this equation:

$$
N_{f}=\frac{\left(a_{0}\right)^{1-m / 2}-\left(a_{c}\right)^{1-m / 2}}{C(m / 2-1) \alpha^{m} \pi^{m / 2} \sigma_{\max }^{m}} .
$$

Values of $C$ and $m$ can be found for ultrahigh strength steels (hot-extrusion die steel H13 falls under this category) from standard references. Size of preexisting cracks $\left(a_{0}\right)$ in heat treated and surface hardened H13 steel, as mentioned above, is generally in the $0.05-0.1 \mathrm{~mm}$ range. Value of the geometry factor (a) for an edge crack is 1.12.

To find the crack size that would trigger an unstable crack growth, we start from the definition of the mode-I stress intensity factor

$$
K_{I}=\alpha f(a / W) \sigma \sqrt{\pi a} .
$$

Neglecting the finite-size factor $f(a / W)$, and knowing that $a=a_{c}$ when $K_{I}=K_{I C}$, we get

$$
a_{c}=\frac{1}{\pi}\left(\frac{K_{I C}}{\alpha \sigma_{\max }}\right)^{2} .
$$

For the simple case of a tube die, treating it as a thick-walled cylinder with internal pressure, the maximum stress would be (Budynas and Nisbett, 2008)

$$
\sigma_{\max }=p\left(\frac{r_{o}{ }^{2}+r_{i}^{2}}{r_{o}{ }^{2}-r_{i}{ }^{2}}\right),
$$

where $r_{o}$ and $r_{i}$ are the outer and inner radii of the tube. Extrusion pressure $p$, considering friction at the billet-container interface but neglecting the relatively small billet-die friction, is given by Groover (2010)

$$
p=\bar{Y}_{f}\left(\varepsilon+2 L / D_{b}\right) .
$$

Here, billet diameter is $D_{b}$, average flow stress of the billet material is $\bar{Y}_{f}$, and instantaneous billet length is $L$. At the beginning of the stroke (when a fresh billet is loaded into the container), $L=L_{0}$; at the end of the stroke, $L=L_{\mathrm{b}}$, where $L_{\mathrm{b}}$ is the length (thickness) of the butt remaining in the container (cut away by a shearing mechanism and removed before loading the next billet into the container). The true strain is given by

$$
\varepsilon=\ln R .
$$

Extrusion ration $R$ can be expressed as 


$$
R=\frac{A_{b}}{n_{1} A_{s}}=\frac{D_{b}^{2}}{n_{1}\left(d_{o}^{2}-d_{i}^{2}\right)},
$$

where $n_{1}$ is the number of cavities in a multi-cavity die. Of course, at $L=L_{0}$ (maximum value of $L$ at the start of the extrusion cycle), $p=p_{\max }$ in equation (8). The inner diameter of the tube is

$$
\mathrm{d}_{\mathrm{i}}=\mathrm{d}_{\mathrm{o}}-2 \mathrm{t} .
$$

Flow stress of the material can be evaluated from the relation (Saha, 2000)

$$
\bar{Y}_{f}=\bar{\sigma}=\bar{\sigma}_{0}\left(\frac{\dot{\bar{\varepsilon}}}{\dot{\overline{\varepsilon_{0}}}}\right)^{m^{*}},
$$

where $\bar{\sigma}_{0}$ is the known flow stress at a known average strain rate $\dot{\bar{\varepsilon}}$. A typical value of the exponent $m^{*}$ at $500^{\circ} \mathrm{C}$ for Al-Mg-Si alloy (the category to which 6063 and other 6xxx alloys of aluminum belong) is 0.125 . At an average strain rate of $50 \mathrm{~s}^{-1}$, the average flow stress for Al6063 was found to be around $40 \mathrm{MPa}$ using the graph shown in Fig. 4 (Sheppard, 1999). The mean strain rate can be found from

$$
\dot{\bar{\varepsilon}}=\frac{6 V}{D_{b}} \ln R
$$

where $V$ is the ram speed and $R$ is the extrusion ratio.

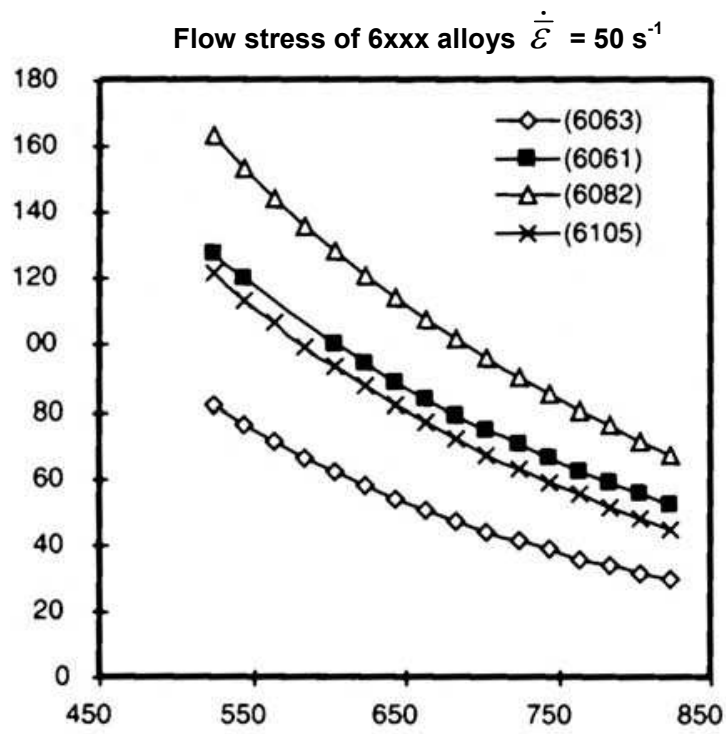

Fig. 4. Flow stress at elevated temperature for $6 x x x$ aluminum alloys, including strain rate effect (Sheppard, 1999) 


\subsection{Probabilistic nature of die life}

Fatigue life and fracture mechanics based models for life prediction are generally deterministic in nature. On the other hand, geometric parameters of an extrusion die and experimentally determined material properties are random variables. Life of an extrusion die is thus largely probabilistic in character. It has been assumed here that geometric dimensions of the die profile and the billet (outer diameter $d$ and thickness $t$ of the tube, length $L$ and diameter $D_{b}$ of the billet) and initial crack size $a_{0}$ (preexisting flaws due to heat treatment and surface hardening) are normally distributed random variables. Mean $(\mu)$ and standard deviation $(\sigma)$ values for profile dimensions are derived from tolerances specified on manufacturer's profile drawing, and those for initial crack size are based on studies about preexisting cracks due to spark erosion in tool steels (Bauser et al., 2006). The data is assumed to be spread within $\pm 3 \sigma$ limits of the mean.

Plane strain fracture toughness $K_{I C}$ of the die material is a strength property and is well represented by a Weibull distribution. Values of $\mu$ and $\sigma$ and the Weibull parameters $m$ and $\theta$ are based on variation in $K_{I C}$ values of tool steels as reported in references such as Sanford (2003) and tool steel manufacturers. Paris constant $C$ of the die material, due to the nature of the Paris law equation, has a log-normal distribution. Mean, variance, and lognormal parameter values $\left(y_{0}\right.$ and $\left.\omega\right)$ are estimated from spread of crack growth data for tool steels, shown in Fig. 5 (Callister, 2006). The other quantities (Paris constant $m$, geometry factor $a$, flow stress exponent $m^{*}$, ram speed $V$, number of cavities $n_{1}$ ) have been treated as constants. Information about the distribution type, average values, standard deviations, etc of all the variables is listed in Table 2.

\begin{tabular}{|c|c|c|c|}
\hline Variable & Distribution & Mean Value & Std Deviation \\
\hline Billet dia $D_{b}$ & Normal & $184 \mathrm{~mm}$ & $0.5 \mathrm{~mm}$ \\
\hline Billet length $L$ & Normal & $660 \mathrm{~mm}$ & $4 \mathrm{~mm}$ \\
\hline Die profile outer dia $d_{o}$ & Normal & $25.4 \mathrm{~mm}$ & $0.1 \mathrm{~mm}$ \\
\hline Die thickness $t$ & Normal & $1.6 \mathrm{~mm}$ & $0.05 \mathrm{~mm}$ \\
\hline Paris constant $C$ & Lognormal & $\begin{array}{c}1.6 \times 10^{-12} \\
\left(y_{0}=1.493 \times 10^{-12}\right)\end{array}$ & $\begin{array}{c}0.192 \times 10^{-12} \\
(\omega=0.229)\end{array}$ \\
\hline Paris exponent $m$ & Constant & 2.85 & - \\
\hline Fracture toughness $K_{I C}$ & Weibull & $\begin{array}{c}83.6 \mathrm{MP} \sqrt{\mathrm{m}} \\
\theta=89.6 \mathrm{MPa} \sqrt{\mathrm{m}}\end{array}$ & $\begin{array}{c}12.54 \mathrm{MPa} \sqrt{\mathrm{m}} \\
m=6.67\end{array}$ \\
\hline Ram speed $V$ & Constant & $5 \mathrm{~mm} / \mathrm{s}$ & - \\
\hline Initial crack size $a_{0}$ & Normal & $0.01 \mathrm{~mm}$ & $0.001 \mathrm{~mm}$ \\
\hline Geometry factor $a$ & Constant & 1.12 & - \\
\hline Number of cavities $n_{1}$ & Constant & 4 & - \\
\hline
\end{tabular}

Table 2. Variables involved, their distributions and values

Usually only room temperature fracture toughness values of $\mathrm{H} 13$ tool steel are available for a few temper conditions (Saha, 2000). Optimum heat treatment (to obtain the best hardness and toughness combination) for $\mathrm{H} 13$ steel being used for hot work dies is tempering to around $550^{\circ} \mathrm{C}$ (Bauser et al., 2006). Average operating temperature in commercial aluminum 
extrusion is about $460^{\circ} \mathrm{C}$. Qamar et al. (2006) developed linear and quadratic polynomial models for the prediction of $K_{I C}$ values for $\mathrm{H} 13$ steels subjected to different tempering routines and used at different operating temperatures. The quadratic model gives a higher correlation coefficient, but the linear model gives more conservative predictions:

$$
\frac{K_{I C}(T)}{H R C(T)}=2.39\left(\frac{C V N(T)}{H R C(T)}\right)+0.17 \quad(\mathrm{MPa} \sqrt{\mathrm{m}}, \mathrm{J})
$$

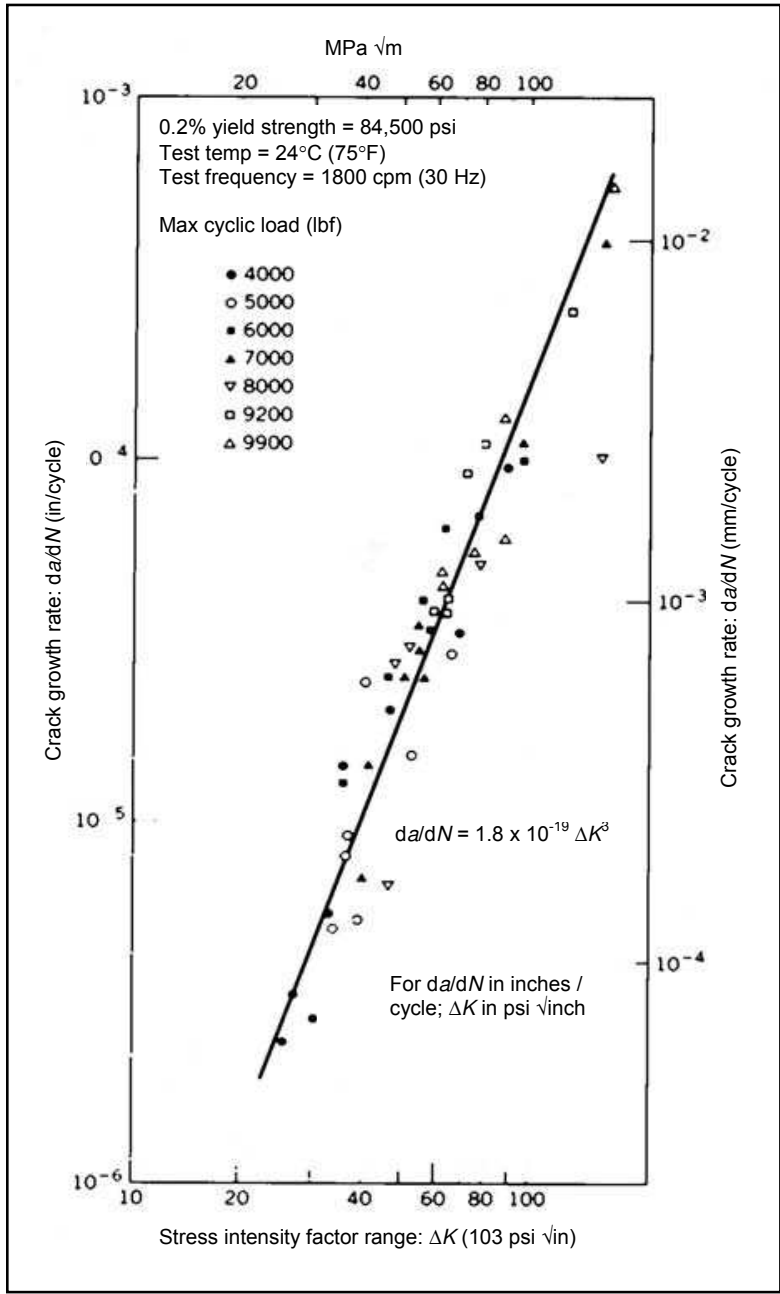

Fig. 5. $\mathrm{d} a / \mathrm{d} N$ vs $\Delta K$ graph (log-log scale) for a Ni-Mo-V steel (Callister, 2006)

Based on hot hardness $H R C(T)$ and hot impact strength $C V N(T)$ data, the predicted fracture toughness value for the temper condition and the working temperature in our case comes out to be around $83.6 \mathrm{MPa} \sqrt{\mathrm{m}}$. 


\subsection{Monte Carlo simulation - fatigue}

The beauty of the Monte Carlo method is that, if a reasonably accurate mathematical model (equation) of a physical process is available, a real experiment can be simulated as many times as required, and the randomness of the variables is guaranteed. The strategy is based upon first establishing a cause-and-effect relationship (such as equations 4 to 13) of the type

$$
N=\varphi\left(X_{1}, X_{2}, \ldots, X_{N}\right),
$$

where $N$ is the tool life (cycles to failure) and $X_{1}, X_{2}, \ldots, X_{N}$ are the various geometrical features and material properties of the die or tooling. Since $X_{1}, X_{2}, \ldots, X_{N}$ are random, the tool life $N$ will also be random in nature.

A large sample $(10,000$ in our case) of random values is then created through generation of independent random numbers $\left(Z_{i}\right.$ or $\left.U_{i}\right)$ using a random number generator (based on a standard normal distribution for normal and lognormal type variables, and a uniform distribution for Weibull type data). These random numbers are then transformed into the required statistical distributions through appropriate transformations. For normally distributed variables such as $D_{b}, d_{0}, t$, etc

$$
X_{i}=\mu_{i}+\sigma_{i} Z_{i}
$$

for variables such as the Paris constant $C$, having a log-normal distribution

$$
X_{i}=\exp \left(\mu_{l}+\sigma_{l} Z_{i}\right)
$$

and for Weibull-distributed data such as $K_{I C}$

$$
X_{i}=\theta\left[\ln \left(1 / U_{i}\right)\right]^{1 / m} .
$$

In these transformation equations, $\mu$ is the mean and $\sigma$ is the standard deviation of the normal variables based on actual data; $\mu_{l}$ and $\sigma_{l}$ are the mean and standard deviations of the log-normal data set; while $m$ and $\theta$ are the shape and scale parameters of the Weibull data (Table-2). Once all the basic variables are randomly generated in this manner, the derived variables (such as $a_{c}, \sigma_{\max }, p, \varepsilon$, etc) are calculated for all the 10,000 instances. Cycles to failure (number of billets) due to fatigue fracture are of course calculated for each set of simulated variables using equation (4).

\subsection{Die life distribution - fatigue}

Reliability is the term used to express the "probability that a component or system will perform satisfactorily for a specified period of time $(t)$ under a given set of working conditions," expressed by $R(t)=P\{t>t\}$. The associated cumulative probability is the "probability that failure takes place at a time less than or equal to $t$," expressed as $F(t)=P\{t$ $\leq t\}$. It is obvious that $F(t)=1-R(t)$. For reliability characterization of life of hot working dies, aging (wear-out) type probability distribution models (normal, lognormal, Weibull, and minimum extreme value) are well postulated. Such failures correspond to increasing failure rates. Each distribution reflects a slightly different failure rate model. Detailed description of curve fitting strategies in the reliability domain can be found in Sheikh et al. (2004).

Weibull distribution is widely used in reliability analyses for describing the distribution of time to failure (machoines and components) and of strength (materials). It is particularly suited for situations where a weakest-link or the largest of many competing flaws is 
responsible for failure. Minimum extreme value (EV) distribution is closely related to the Weibull distribution and is thus often used for similar purposes, such as representation of failure times. Lognormal and normal distributions are also closely related to each other, in the same way as Weibull and minimum EV distributions are. The mathematical ease to work with a Weibull model when deciding optimal die replacement strategies or determining number of dies needed for a given production run makes it more attractive.

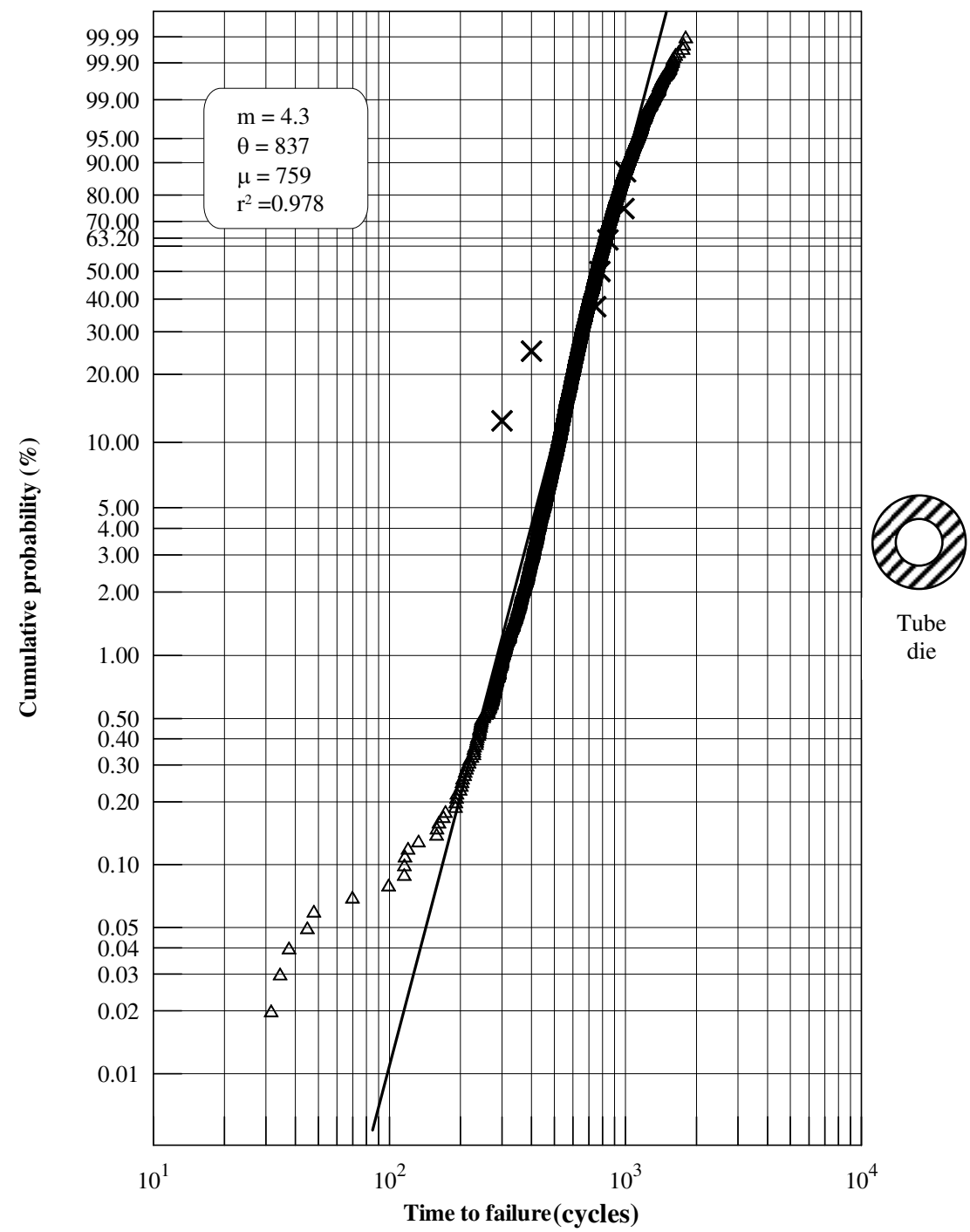

Fig. 6. Weibull model of fracture-failure simulation for the tube die

Once the simulated predictions for die failure by fracture are obtained, curve fitting is done to obtain standard probability distributions used in reliability studies (normal, lognormal, 
Weibull, and minimum extreme value). Weibull distribution, shown in Fig. 6, gives the best overall goodness of fit (correlation coefficient of $r^{2}=97.8 \%$ ), although lognormal or even normal model cannot be ignored completely. Minimum extreme value distribution does not appear to be a good representation of die reliability. As evidenced by the graph, the Weibull line provides a good fit not only for the simulated data but also for the actual die life data (represented by $\mathrm{x}$ on the figure). Shape parameter for the Weibull line, representing the scatter in die life, came out to be $m=4.3$. Value of the scale parameter $\theta$ was 837 billets (cycles). Average die life is linked with the scale parameter and the scatter parameter by the equation

$$
\operatorname{MTTF}=\theta \Gamma(1+1 / m),
$$

where $\Gamma(\quad)$ is the gamma function. Thus, based on the simulation results, $M T T F=838 \Gamma(1+1 / 4.3)=759$ cycles, whereas the actual MTTF due to fracture failures is 722 cycles.

\section{Wear failure}

Saha $(1998 ; 2000)$ studied the effect of extrusion speed and billet length on wear at the die (cap) and the mandrel shown in Fig. 7. A thin walled square tube of Al-6063 was extruded through heat treated and nitrided H13 steel die. Average billet temperature was $460^{\circ} \mathrm{C}$. Higher extrusion speeds are expected to increase wear due to abrasion. Longer billet lengths generate larger friction surfaces, the increased friction promoting wear. Effect of ram speed and billet length on wear at die land was therefore studied.

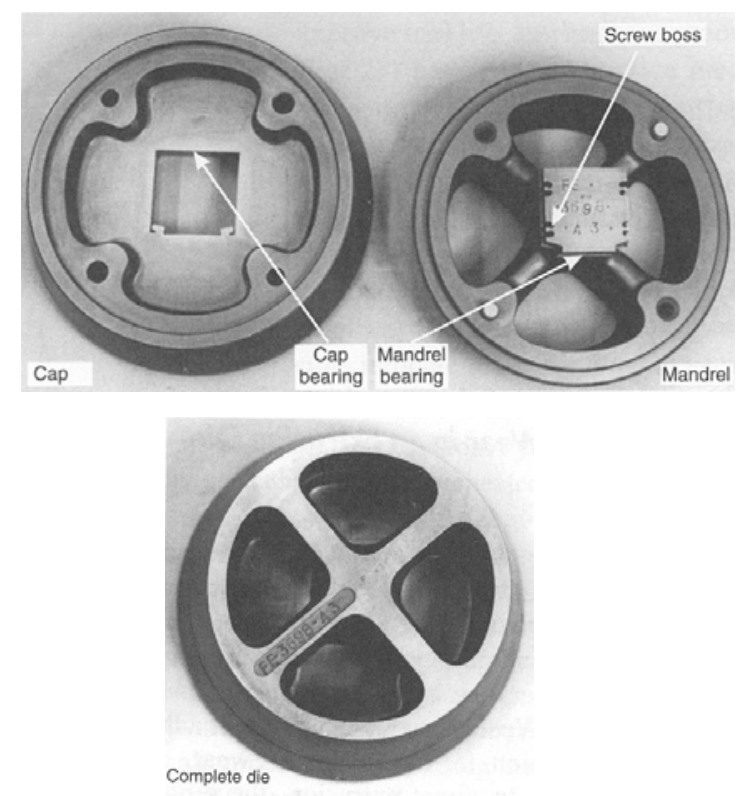

Fig. 7. Bearing surface on the die (cap) and mandrel, and the assembled die set used for wear experiments in hot aluminum extrusion (Saha, 2000) 

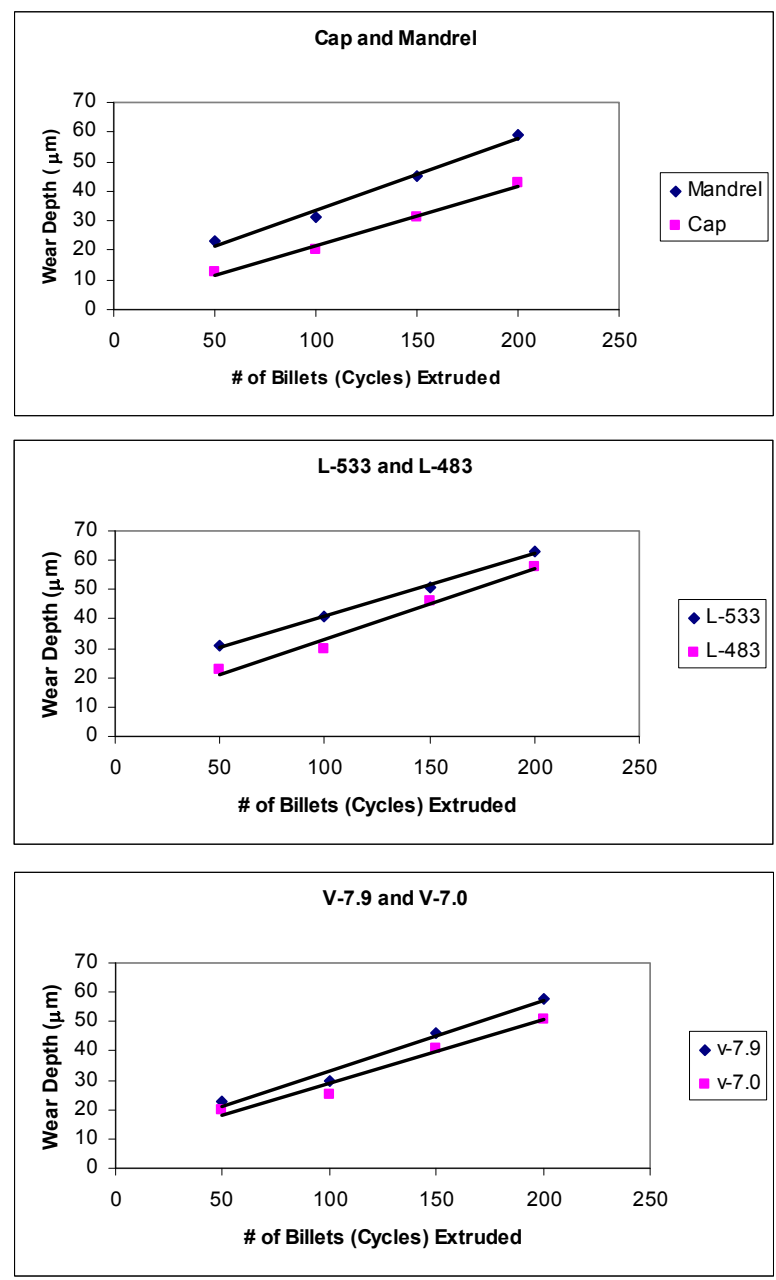

Fig. 8. Increasing wear depth at mandrel and cap of a hollow die for varying billet length and ram speed (billet temperature is $460^{\circ} \mathrm{C}$ ); variation suggests linear behavior; data source Saha (2000)

Wear depth from these experiments (Saha, 2000) have been replotted in Fig. 8. The plots show that wear progresses almost linearly as more billets are extruded. A simple die wear model would thus be

$$
W=a t+c,
$$

where $W$ is the wear depth in microns $(\mu \mathrm{m}), t$ is the number of extrusion cycles (billets extruded), and $a$ and $c$ are the slope and intercept of the straight line representing the progressive wear behavior. As a new die is perfectly smooth, with no wear at the bearing surface, we have $W=0$ at $t=0$. The intercept would thus be zero. The model would then simplify to 


$$
W_{f}=a t_{f}
$$

$W_{f}$ signifies the limiting amount of wear leading to die failure, and $t_{f}$ is the number of billets (cycles) extruded before reaching $W_{f}$.

\subsection{Parameter determination}

Actual die failure data (due to wear at the die land) has been collected for the box profile described earlier. Die failure data (number of billets extruded before die was rejected due to excessive wear) of 21 initially-identical dies are given in Table 3. The average die life (MTTF) was 508 extrusion cycles. Based on the manufacturing tolerance for minimum wall thickness, it was determined that a failure wear of $W_{f}=75 \mu \mathrm{m}$ on the bearing surface of the die or the mandrel would lead to rejection. This means that each time a die failure occurred, wear had reached this limiting value. Slope $(a)$ of the wear line was evaluated for each die rejection from the cycles (number of billets) to failure and limiting wear data. Mean and standard deviation values of this parameter (a) came out to be $0.169 \mathrm{~mm}$ and 0.035 . As demonstrated by Fig. 9, wear failure data for this box die are well represented by the Weibull distribution.

\begin{tabular}{|c|c|c|c|}
\hline Failure \# & Cycles to Failure & Failure \# & Cycles to Failure \\
\hline 1 & 392 & 12 & 611 \\
\hline 2 & 642 & 13 & 295 \\
\hline 3 & 598 & 14 & 341 \\
\hline 4 & 713 & 15 & 525 \\
\hline 5 & 576 & 16 & 402 \\
\hline 6 & 335 & 17 & 356 \\
\hline 7 & 340 & 18 & 282 \\
\hline 8 & 548 & 19 & 227 \\
\hline 9 & 480 & 20 & 658 \\
\hline 10 & 725 & 21 & 1050 \\
\hline 11 & 559 & \multicolumn{2}{|c}{} \\
\hline
\end{tabular}

Table 3. Various instances of number of billets (cycles) to failure for the box-die studied, indicating when surface wear reaches a critical value of $W_{f}=75$ microns

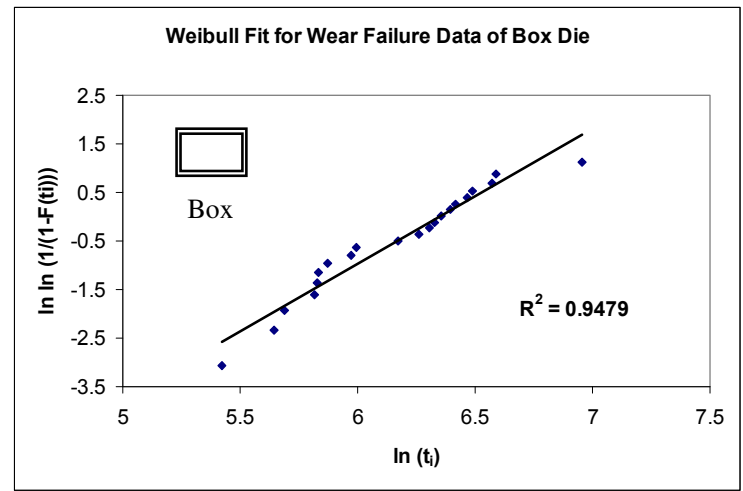

Fig. 9. Wear failure data for the box die are well represented by the Weibull distribution $\left(r^{2}=94.8 \%\right)$ 


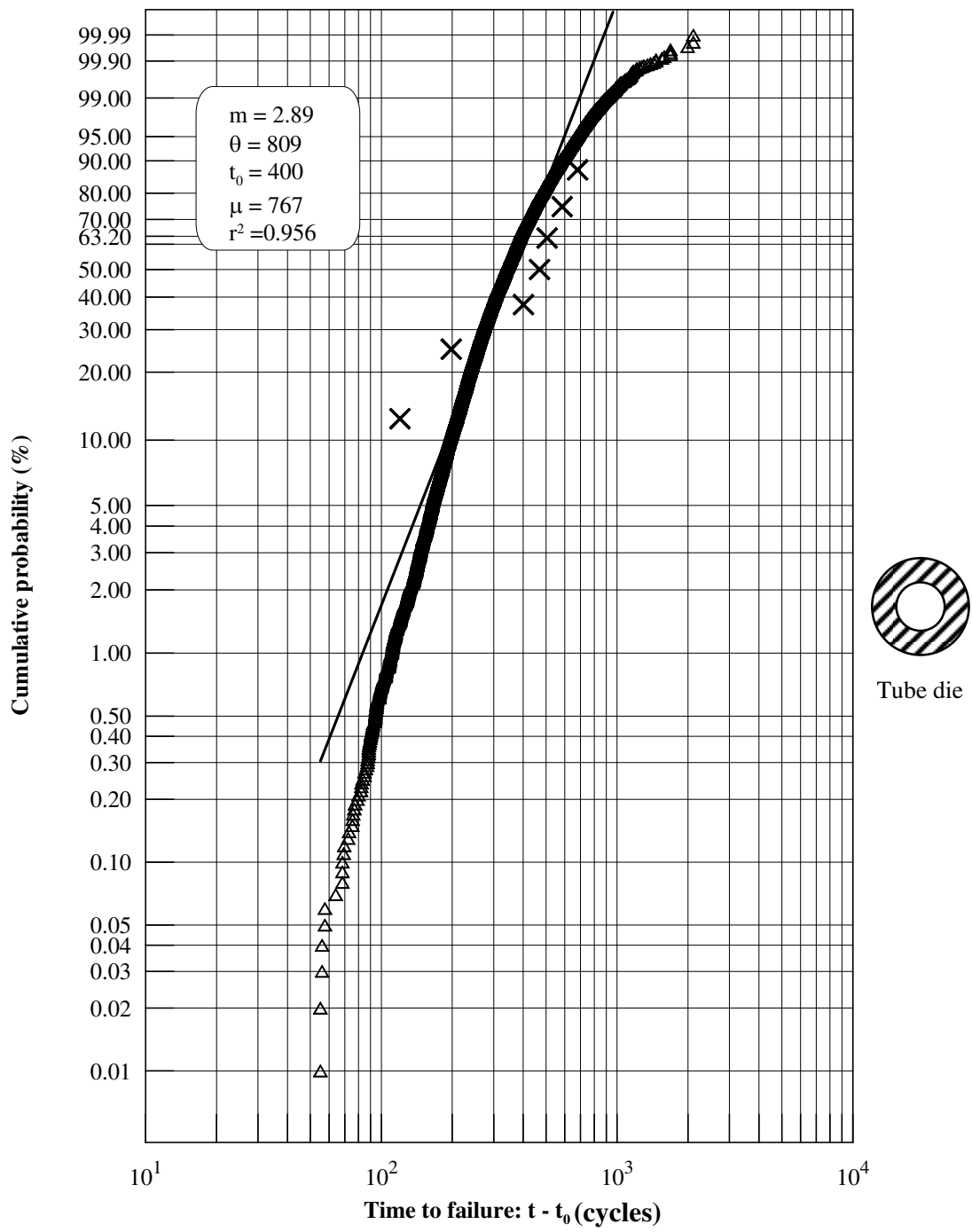

Fig. 10. Plot showing simulated wear life data and the fitted 3-parameter Weibull line for the tube die

\subsection{Monte Carlo simulation - wear}

Failure data of the box die were used only to generate the wear model desribed above. Monte Carlo simulation was then carried out for the same hollow die (simple tube) whose fracture simulation was presented before. It was assumed that the distribution (mean and standard deviation) of the slope $m$ characterizing wear behavior remains the same for all H13 steel dies used in hot aluminum extrusion. 10,000 standard normal random numbers were generated as before, and were transformed to random values of the slope $m$, based on its $\mu$ and $\sigma$ values determined above. A limiting wear value of 125 microns was used, 
determined from the dimensional tolerances for the tube die. Wear life of the die was then evaluated for each simulated instance of $m$, using equation (21). Compared to an actual MTTF value of 722 billets, the simulated life (based on wear failures only) came out to be 767 cycles. We know from the actual failure history of this die that wear was not a dominant failure mode. This fact is confirmed by the Weibull fit to the simulated data (Fig. 10), yielding a lower correlation coefficient of $95.6 \%$ (as against $r^{2}=97.8 \%$ for fracture failure).

\section{Combined fracture and wear}

As explained earlier, various failure mechanisms are operating simultaneously on the die during its operative life. Fracture and wear are thus competing against each other. Final die failure takes place either when a preexisting crack (of size $a_{\mathrm{o}}$ ) reaches the critical crack size $\left(a_{c}\right)$, or when wear on the die land reaches the limiting value $\left(W_{f}\right)$. It is assumed here that the two failure modes progress independently of each other, until one of them becomes dominant and takes over. However, in reality, the failure modes may be inter-dependent in a rather complicated manner.

The number of cycles to failure under the competing fracture-wear mode was determined from the relation

$$
t=\min \left(t_{F}, t_{W}\right),
$$

where $t_{F}$ is the simulated fracture life, $t_{W}$ is the wear life, and $t$ is the final predicted life, representing the failure (fracture or wear) that occurs earlier. The MTTF of this simulated fracture-wear die life was 717 billets. In comparison with the actual average life of 722 billets, this is a very close prediction. Weibull distribution was once again found to be the best fitted to the simulated die life data, with a coefficient of correlation value of $r^{2}=98.5 \%$, as shown in Fig. 11. This combined fracture-wear model is obviously the best representation of die failure, yielding a shape parameter $m=4.99$ and a scale parameter $\theta=786$ billets.

\section{Conclusions}

This chapter presents a simulation strategy for prediction of service life of metalworking dies and tools that undergo fracture and wear. A concise review of fracture and wear faliures of hot-work extrusion dies, and of the Monte Carlo simulation strategy has been presented. Failure mechanisms under fatigue and wear are briefly explained, using basic fracture mechanics and tribology principles. Mathematical models for the two faliure types have been explained. Die life and related material and geometrical parameters have been treated as random variables, the approach being closer to reality as compared with the deterministic models usually employed. Monte Carlo simulation has been carried out to predict the life of an extrusion die, Paris law providing the physical-mathematical model for estimation of fatigue life of the die in terms of number of cycles to failure (number of billets extruded). Correlation models developed earlier by the authors have been utilized to estimate the value of fracture toughness $\left(K_{I C}\right)$ of $\mathrm{H} 13$ hot work die steel under typical tempering and operating temperature conditions. Failure history of an actual simple hollow die from the aluminum extrusion industry has been used as a case study.

The resulting (simulated) die life observations are adequately represented by a Weibull probability model with shape parameter $m=4.3$ and scale parameter $\theta=837$ cycles (billets), an average die life of 759 cycles (as against the actual MTTF of 722 cycles), and a correlation coefficient of $r^{2}=97.8 \%$. A failure model based on surface wear has also been developed, 


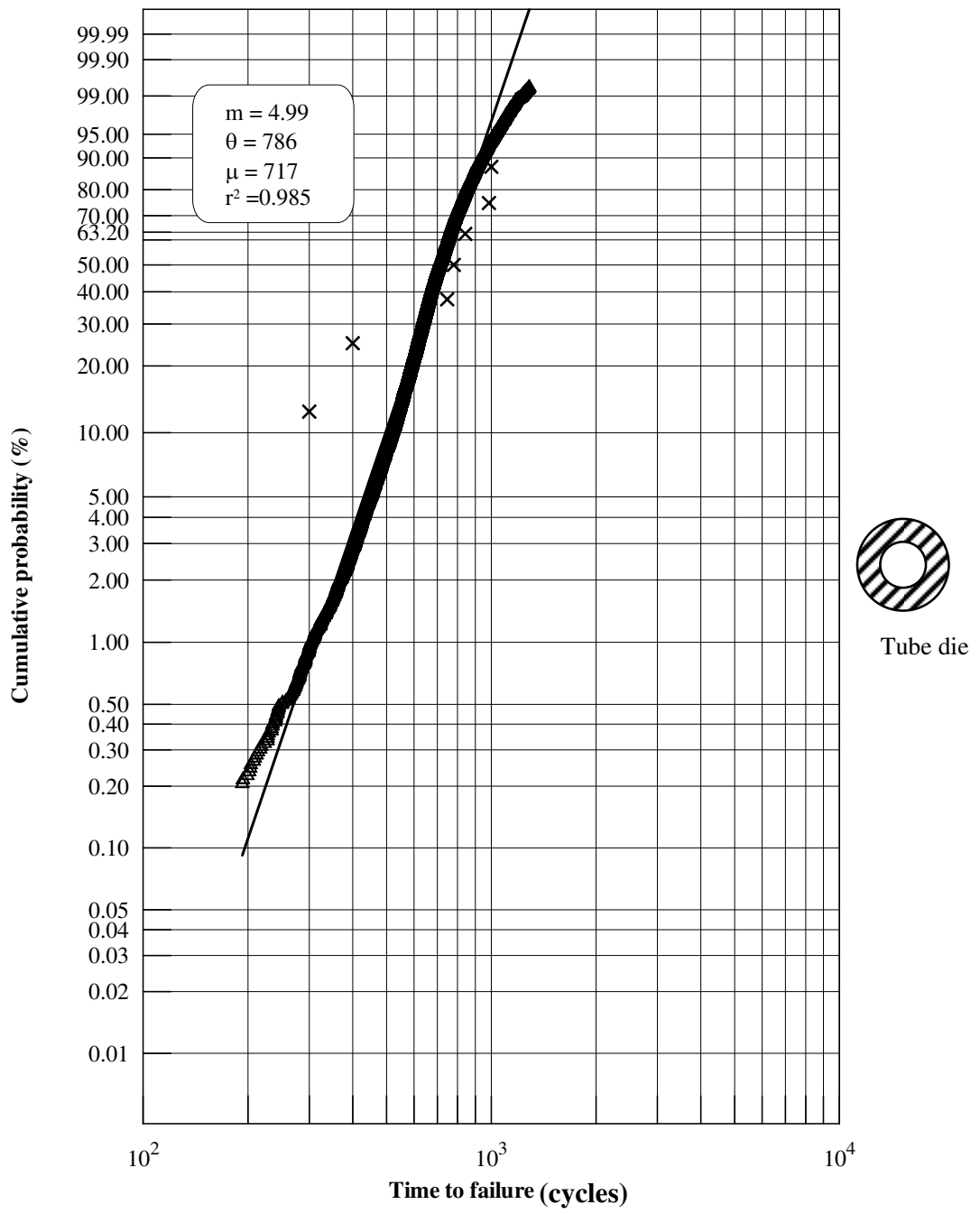

Fig. 11. Plot of Weibull model for simulated combined life data (fracture-wear competing mode) for the tube die

using actual wear data of a hollow box die. Using this linear wear-failure model, Monte Carlo simulation has been carried out to predict the die life of the tube die. The simulation yielded a Weibull fit with $m=2.89, \theta=809$ cycles, MTTF $=767$ cycles, and $r^{2}=95.6 \%$. This lower goodness of fit for wear matches well with failure records, as the tube die did not fail frequently due to wear in actual practice. The combined fracture-wear failure model yielded the best simulation, with $m=4.99, \theta=786$ cycles, MTTF $=717$ cycles, and $r^{2}=98.5 \%$.

The strategy outlined here can be easily adapted to forecast the fracture, wear, or combined fracture-wear life of cold-work or hot-work metal-forming dies (especially extrusion) that are made from tool steels, are subjected to different heat treatment routines, and are used at different operating temperatures. $K_{I C}-C V N$ correlations developed by the authors (Qamar et 
al.; 2006) can bed used to find the values of fracture toughness of heat-treated tool steels. The work can be extended to cover more complex profiles, extrusion pressure for a specific profile being estimated using its shape complexity (Qamar et al., 2004). Expected service life can thus be predicted for a die of a given profile even before the die is used. The industry can employ the life prediction scheme to develop optimum die replacement strategies. This can contribute to serious reduction in warehousing costs, and can prevent unnecessary downtime due to unavailability of a certain die profile, thereby increasing productivity and client satisfaction. Analysis of die-life simulation results can also help improve die design against fracture and wear failures.

\subsection{Future work; special note}

A simulation is as good as the underlying model. Two basic simplifications are made in this study: using the model of an edge crack in a flat plate whereas the actual die is a hollow cylinder, and disregarding the correction factor for finite width. $K_{I C}-C V N$ correlations used for estimation of hot fracture toughness may need more experimental work and refinement. Paris equation parameters $C$ and $m$ used here are for a generic hot-work tool steel; actual values of these constants may be needed for H13 tool steel (not available till now). With these refinements, the model can be initially used for more accurate simulation of failures of dies of simple geometry. The simulation strategy could then be used to forecast failures of more complex dies by employing the complexity-pressure models developed earlier by the authors (Qamar et al., 2004). A relatively sound replacement strategy for dies and related tooling can thus be formulated.

\section{References}

Anderson, T.L. (2005) Fracture Mechanics Fundamentals and Applications, 3rd edition, Taylor and Francis, ISBN-13 978-0-8493-1656-2, Boca Raton, Louisiana

Arif, A.F.M. ; Sheikh, A.K. ; Qamar, S.Z. ; Al-Fuhaid, K.M. (2003) A study of die failure mechanisms in aluminum extrusion, Journal of Materials Processing Technology, Vol. 134, No. 3, p 318-328

Barsom, J.M.; Rolfe, S.T. (1970) Correlations between $K_{I C}$ and Charpy V-notch test results in the transition-temperature range, Impact Testing of Metals, ASTM STP 466, American Society for Testing and Materials, Philadelphia, p 281-302

Bauser, M. ; Sauer, G. ; Siegert, K. (2006) Extrusion, 2nd edition, ASM International, ISBN-13 : 978-0-87170-837-3, Materials Park, Ohio

Björk T, Westergard R, Hogmark S (2001) Wear of surface treated dies for aluminum extrusion - a case study, Wear, Vol. 249, p 316-323

Budynas, R.G.; Nisbett J.K. (2008) Shigley's Mechanical Engineering Design, 8th edition, McGraw-Hill, ISBN 978-007-125763-3, Singapore

Callister, W.D. (2006) Materials Science and Engineering: An Introduction, 6th edition, John Wiley, ISBN 8126508132, New York

Cosenza, C.; Fratini, L.; Pasta, A.; Micari, F. (2004) Damage and fracture study of cold extrusion dies, Engineering Fracture Mechanics, Vol. 71, p 1021-1033

Gouveia, P.A.; Rodrigues, J.M.C.; Martins, P.A.F. (2000) Ductile fracture in metalworking: experimental and theoretical research, Journal of Materials Processing Technology, Vol. 101, No. 1-3 (April 2000), p 52-63

Groover, P.G. (2010) Fundamentals of Modern Manufacturing: Materials, Processes, and Systems, John Wiley, ISBN-13 978-0470467008, New York 
Hambli, R.; Badie-Levet, D.; (2000) Damage and fracture simulation during the extrusion process, Computer Methods in Applied Mechanics and Engineering, Vol. 186, No. 1, p 109-120

Laue, K. ; Stenger, H. (1981) Extrusion: Processes, Machinery, Tooling, American Society for Metals, ISBN 0-87170-094-8, Metals Park, Ohio

Lee, G-A.; Im, Y-T.; (1999) Finite element investigation of the wear and elastic deformation of dies in metal forming, Journal of Materials Processing Technology, Vol 89-90 (May 1999), p 123-127

Müller, K.B. (2002) Deposition of hard films on hot-working steel dies for aluminum, Journal of Materials Processing Technology, Vol. 130-131, p 432-437

Nanninga, N.; White, C. (2009) The relationship between extrusion die line roughness and high cycle fatigue life of an AA6082 alloy, International Journal of Fatigue, Vol. 31, No. 7 (July 2009), p 1215-1224

Pöhlandt, K.; Kuehl, R. (1989) Materials Testing for the Metal Forming Industry, SpringerVerlag, ISBN 0387506519, Berlin

Qamar, S.Z.; Arif, A.F.M.; Sheikh, A.K. (2004) A new definition of shape complexity for metal extrusion, Journal of Materials Processing Technology, Vol. 155-156, No. 30 (November 2004), p 1734-1739

Qamar, S.Z.; Sheikh, A.K.; Arif, A.F.M.; Pervez, T. (2006) Regression-based CVN-KIC models for hot work tool steels, Materials Science and Engineering A, Vol. 430, No. 1-2 (August 2006), p 208-215

Saha P K (1998) Thermodynamics and tribology in aluminum extrusion, Wear, Vol. 218, p 179-190

Saha, P. K. (2000) Aluminum Extrusion Technology, ASM International, ISBN-13 9780871706447 Materials Park, Ohio

Sanford, R.J. (2003) Principles of Fracture Mechanics, Pearson Education, ISBN-13 9780130929921, Upper Saddle River, New Jersey

Sheikh AK, Arif AFM, Qamar SZ (2004) A probabilistic study of failures of solid and hollow dies in hot aluminum extrusion, Journal of Materials Processing Technology, Vol. 155156, No. 30 (November 2004), p 1740-1748

Sheppard, T. (1999) Extrusion of Aluminum Alloys, Kluwer Academic Publishers, ISBN 0412 59070 0, Dordrecht

So, H.; Chen, H.M.; Chen, L.W. (2008) Extrusion wear and transition of wear mechanisms of steel, Wear, Vol. 265, No. 7-8 (September 2008), p 1142-1148

Sudhakar, K.V.; (2002) Micromechanics of fracture in extrusion die punch, Engineering Failure Analysis, Vol. 9, p 159-165

Terčelj, M.; Smolej, A.; Fajfar, P.; Turk R. (2007) Laboratory assessment of wear on nitrided surfaces of dies for hot extrusion of aluminium, Tribology International, Vol. 40, No. 2 (February 2007), p 374-384

Thedja W W, Muller B K, Ruppin D (1992) Tribological processes on the die land area during extrusion of A16063," Proceedings 5th International Aluminum Extrusion Technology Seminar, Aluminum Association \& Aluminum Extruders Council

Tseronis, D. ; Sideris, I.F. ; Medrea, C.; Chicinas, I. (2008) Microscopic examination of the fracture surfaces of an $\mathrm{H} 13$ hot extrusion die due to failure at the initial usage stage, Key Engineering Materials, Vol. 367 (2008), p 177-184

Yoh, E-G.; Kim, Y-I.; Lee, Y-S.; Park, H-J.; Na, K-H.; (2002) Integrated analysis for die design including brittle damage evolution, Journal of Materials Processing Technology, Vol. 130-131 (December 2002), p 647-652 


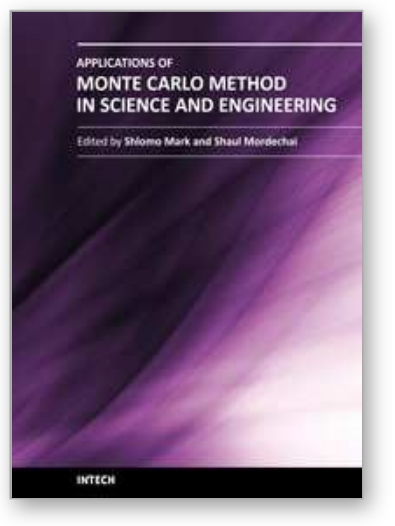

\section{Applications of Monte Carlo Method in Science and Engineering \\ Edited by Prof. Shaul Mordechai}

ISBN 978-953-307-691-1

Hard cover, 950 pages

Publisher InTech

Published online 28, February, 2011

Published in print edition February, 2011

In this book, Applications of Monte Carlo Method in Science and Engineering, we further expose the broad range of applications of Monte Carlo simulation in the fields of Quantum Physics, Statistical Physics, Reliability, Medical Physics, Polycrystalline Materials, Ising Model, Chemistry, Agriculture, Food Processing, X-ray Imaging, Electron Dynamics in Doped Semiconductors, Metallurgy, Remote Sensing and much more diverse topics. The book chapters included in this volume clearly reflect the current scientific importance of Monte Carlo techniques in various fields of research.

\section{How to reference}

In order to correctly reference this scholarly work, feel free to copy and paste the following:

Sayyad Zahid Qamar, Anwar Khalil Sheikh, Tasneem Pervez and Abul Fazal M. Arif (2011). Using Monte Carlo Simulation for Prediction of Tool Life, Applications of Monte Carlo Method in Science and Engineering, Prof. Shaul Mordechai (Ed.), ISBN: 978-953-307-691-1, InTech, Available from:

http://www.intechopen.com/books/applications-of-monte-carlo-method-in-science-and-engineering/usingmonte-carlo-simulation-for-prediction-of-tool-life

\section{INTECH}

open science | open minds

\section{InTech Europe}

University Campus STeP Ri

Slavka Krautzeka 83/A

51000 Rijeka, Croatia

Phone: +385 (51) 770447

Fax: +385 (51) 686166

www.intechopen.com

\section{InTech China}

Unit 405, Office Block, Hotel Equatorial Shanghai

No.65, Yan An Road (West), Shanghai, 200040, China

中国上海市延安西路65号上海国际贵都大饭店办公楼 405 单元

Phone: +86-21-62489820

Fax: $+86-21-62489821$ 
(C) 2011 The Author(s). Licensee IntechOpen. This chapter is distributed under the terms of the Creative Commons Attribution-NonCommercialShareAlike-3.0 License, which permits use, distribution and reproduction for non-commercial purposes, provided the original is properly cited and derivative works building on this content are distributed under the same license. 